Technological University Dublin ARROW@TU Dublin

\title{
Using Pre-Lecture Activities to Enhance Learner Engagement in a Large Group Setting
}

\author{
Gemma Kinsella \\ Technological University Dublin, gemma.kinsella@tudublin.ie \\ C. Mahon \\ Maynooth University \\ S. Lillis \\ Lillis \& Associates, Dublin
}

Follow this and additional works at: https://arrow.tudublin.ie/ltcart

Part of the Education Commons

\section{Recommended Citation}

Kinsella, G.K., Mahon, C. \& Lillis, S. (2017). Using pre-lecture activities to enhance learner engagement in a large group setting. Active Learning in Higher Education, vol 18. no. 3, pp. 231-242. doi:10.1177/

1469787417715205

This Article is brought to you for free and open access by

the Learning Teaching \& Assessment at ARROW@TU

Dublin. It has been accepted for inclusion in Articles by an authorized administrator of ARROW@TU Dublin. For more information, please contact

arrow.admin@tudublin.ie, aisling.coyne@tudublin.ie, gerard.connolly@tudublin.ie.

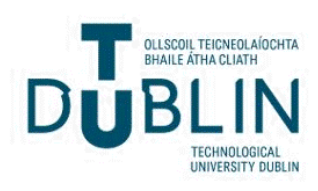




\title{
Using pre-lecture activities to enhance learner engagement in a large group setting
}

Active Learning in Higher Education

(c) The Author(s) 2017

Reprints and permissions:

Sagepub.co.uk/journalsPermissions.nav DOI: $10.1177 / 1469787417715205$ journals.sagepub.com/home/alh

\$SAGE

\section{Gemma K Kinsella}

Dublin Institute of Technology, Ireland

Catherine Mahon

Maynooth University (National University of Ir eland Maynooth), Ireland

\section{Seam us Lillis}

Dr Seamus Lillis \& Associates, UKDublin, Ireland

\begin{abstract}
The disadvantage to students of beginning a module with no prior knowledge or inaccurate knowledge is well documented. For learners, the development of the necessary prior knowledge to facilitate their learning is essential. The use of screencasts, whether prior to or during class, is becoming more widespread. There is a need, however, to better understand how these are used and whether or not there is any impact on overall learner engagement and academic achievement when a component with instantaneous feedback (such as a multiple choice quiz) is embedded into the pre-lecture screencast activity. In this study, pre-learning activities consisting of screencasts and multiple choice quizzes were introduced to improve student engagement with the topic, gauge common misconceptions and give timely feedback to the students. An examination of screencast usage indicated that students did not predominantly nor exclusively employ the resources as originally intended, that is, in advance of lectures. Rather, students continued to access the activities across the module and often after the associated lecture. Implications are discussed with an acknowledgement of the importance of taking into account how learners prefer to use resources when designing and introducing new activities to modules.
\end{abstract}

\section{Keywords}

large group teaching, learner engagement, multiple choice quizzes, prior knowledge, screencasts

\section{Identifying and enhancing learner prior knowledge - what do learners know already and how can this help them?}

To find ways to support student learning, educators are increasingly turning their attention to the very roots of the learning experience, that is, to the knowledge, skills, environments and processes already possessed and encountered by the learner before the new, to-be-learned material is introduced (Coppola and Krajcik, 2014). Although such awareness of the importance of prior knowledge is not a recent emergence (Ausubel, 1968), interest in what learners know in advance of

\section{Corresponding author:}

Gemma K Kinsella, School of Food Science and Environmental Health, College of Sciences and Health, Dublin Institute of Technology, Cathal Brugha Sreet, Dublin 1, Ireland.

Email: Gemmakinsella@dit.ie 
entering the classroom and how this impacts their future learning has gathered considerable pace. Over the past few years, the flipped classroom approach has been recognised as a method that can help learners to familiarise themselves with course content before attending face-to-face sessions (Herreid and Schiller, 2013). Utilising the technique at a rudimentary level, learners are encouraged to watch videos or read texts that have a direct bearing on the material to be explored in upcoming classes (Davies et al., 2013). Positive outcomes for students completing courses in which the flipped classroom method has been used include improvements in academic achievement and strengthening of learner engagement (Baepler et al., 2014; Fulton, 2012; Gilboy et al., 2015).

When it comes to previous knowledge, one of the most consistent findings across disciplines is that learners who begin a module with at least some accurate information related to that subject (perhaps acquired from studying the subject at post-primary level) are in an advantageous position when it comes to learning new information (Lasry et al., 2014; Thompson and Zamboanga, 2004). These students have been observed to score higher marks on assessment tasks when compared to students with little or no prior knowledge (Lopez et al., 2014; Seery, 2009). Conversely, students who commence a new course with no prior knowledge or with discipline-relevant information that is unreliable or error-strewn (e.g. misconceptions) can inadvertently find themselves at an immediate disadvantage, most notably in terms of experiencing difficulties in remembering new information that contradicts what they previously thought (Kowalski and Kujawski Taylor, 2009). The potential obstacles to learning associated with holding inaccurate knowledge as a new course participant may not be confined solely to the first year of the programme as there may also be implications for later years of study (Badenhorst et al., 2015). Bearing this in mind, extending our knowledge, first, of effective approaches to help all students develop the necessary prior knowledge to facilitate their learning, not only in the primary year of study but additionally in subsequent years, and, second, furthering our understanding as to how these approaches can be efficiently implemented within the higher education context become an increasing priority for educators. Furthermore, the priority may be heightened when it comes to large classes in particular, which often translate to groups of learners from different backgrounds with various degrees of prior subject knowledge, including some with none at all (Exeter et al., 2010).

Among the new information that learners may be expected to master will be disciplinespecific concepts. Coticone (2013) highlighted that undergraduates are frequently faced with an ever-increasing set of novel terms to learn, sometimes with little or no comprehension of the relevance or application of these terms. Seery and Donnelly (2012) piloted a pre-lecture initiative designed to reduce the demands associated with learning new terminology and concepts in lectures. Prior to each lecture, students completed a short audiovisual resource posted on the virtual learning environment module space. Any terms or concepts that would be pivotal to the upcoming lecture were explained in the resource, followed by a quiz designed to provide the learners with feedback on their knowledge leading into the class and address likely areas of confusion. In comparison with previous years, the researchers found that the average midsemester and end-of-module examination performance scores of the students increased following the introduction of the pre-lecture resources, with the gains in performance most marked for learners with no previous subject knowledge (see also Moravec et al., 2010; Muller et al., 2008; Stull et al., 2011). Overall, these findings suggest that rather than starting from zero, pre-lecture activities can help to establish a platform from which further learning can potentially escalate, thereby helping to counteract issues with prior knowledge (e.g. a lack of knowledge or erroneous knowledge). In addition, they can also be used for content that is known to be difficult or ambiguous for students, and the performance observed on these resources may provide course lecturers with a more realistic estimate of the learners' prior knowledge which can be used to inform future lectures. 


\section{Developing existing knowledge through use of technology}

A consistent thread between many of the recent studies that have explored ways to help new learners build their prior knowledge has been the use of technology-based resources. Indeed, it has been suggested that eLearning tools have changed the traditional educational process (Mohorovičić and Tijan, 2011). Examples of some of these tools include screencasts. These are recordings made available for learners (often via online environments) which traditionally comprise visual elements such as images, diagrams, text, animations and slides, alongside audio components, for example, a lecturer talking through the featured content. Some of the benefits offered by screencasts are that students can learn at their own speed by stopping, starting and replaying the screencast as desired.

A potential limitation of some screencasts is that they may be described as quite passive learning activities, especially if students are only watching, listening and never requested to actually do something in relation to the material. Incorporating an associated multiple choice quiz (MCQ) as part of the screencast resource is one way of attempting to ensure that the activity is not merely a passive one for students but that there is at least a little scope to try and apply the material in a way that is not going to be too daunting for students or demanding in terms of their time. The use of an MCQ prior to lectures can be cited as an example of a growing trend to use such activities as learning tools when students are first beginning a new topic, rather than as assessment methods at the end of the topic (Cantor et al., 2015; Wijtmans et al., 2014).

Morris and Chikwa (2014) reported some preliminary evidence to suggest that the use of screencasts may be associated with gains in module marks. In this study, the screencasts did not function as pre-lecture resources but rather supplementary resources where challenging topics highlighted by the students themselves following the lectures could be explored again with additional explanation. Aside from academic achievement, less is known about the other benefits that pre-lecture screencasts may potentially offer for learners. Engagement is one such area. This may include engagement with the course materials or the curriculum or even engagement in terms of communication and interaction with the course facilitator. With large classes (which could range from 100 to 1000 students in a class), from anecdotal experiences many students express feeling daunted and anonymous in the crowd. For some, this may restrict their engagement with the topic and the lecturer - a concern that has been highlighted in the literature on large group teaching (Mulryan-Kyne, 2010). As a result, 'it is important for instructors in large classes to examine what they might do to more deeply engage students to promote learning' (Lane and Harris, 2015: 83). When it comes to engagement, Exeter et al. (2010) proposed that engagement necessitates that lecturers ensure that the lecture tasks are included with the intention of strengthening learner understanding of the material. It may be suggested that this could be extended a step further to include tasks outside of the lecture as well in the vein of the flipped classroom approach. Screencasts may be an example of a tool that could potentially be used outside of the classroom to help students comprehend course content while simultaneously helping to strengthen channels of communication between the learners and the lecturer and enhance student engagement.

As an alternative, or additional tool, clickers also offer an efficient way to hold all students accountable for pre-class preparation, reading and homework, by assessing comprehension at the beginning of class meetings (Knight and Wood, 2005). Some research indicates that using clickers can help to reinforce student engagement in daily study. For example, Caldwell et al. (2006) found that students who were regularly quizzed on readings prepared more for class. The authors did underline, though, that students did not seem to mind this additional task providing they earned something contributing to their final marks. Instructors have also reported that when clicker scores account for $15 \%$ or more of the course grade, attendance levels rise, preparation for quizzes becomes more serious and students appear noticeably more alert during class (Burnstein and 
Lederman, 2001). From a teaching perspective, lecturers can look over the answers from a clicker quiz to gauge the appropriate speed to deliver new material. As an example, if the whole class correctly answers a question, then perhaps a new topic can be commenced. Clickers typically have either a benign or positive effect on student performance on examinations, depending on the method and extent of their use, and can create a more positive and active atmosphere in the large classroom (Vital, 2012).

Although the body of research about clickers is relatively plentiful (Campbell and Monk, 2015), comparatively less is known about the use of screencasts. The study described in this article was undertaken to add to the knowledge base in this area. There is still more that we need to understand about how learners utilise screencasts, particularly when used prior to lectures and in advance of any assessment(s). It cannot be taken for granted that simply because screencasts are available before the lecture, learners will actually use them before coming to class. Completion rates of preparatory tasks in general (for instance, pre-class reading) in some contexts can be quite low (see Burchfield and Sappington, 2000; Clump and Doll, 2007). The large group learning environment may, or may not, be conducive to prior lecture screencast use. Of relevance here is a finding by Opdecam and Everaert (2012) that students on a large lecture course committed less hours to before-class preparation than learners studying the same course but taught in smaller groups. Thus, there is need to investigate whether students will find the time to access screencasts as part of their before-lecture preparation. Broadly speaking then, although the literature would suggest that there are certainly potential benefits to introducing pre-lecture tasks (e.g. Seery and Donnelly, 2012), the benefits are arguably nullified somewhat if students do not use the resources in the intended manner. Struyven et al. (2012) advised that with any new task or approach, students' perceptions of the task may impact the extent to which they engage with the task, resulting in learning which may be very different to that envisaged by the lecturer.

No matter which technological activity is pursued, as emphasised by Nicol and MacfarlaneDick (2004), it is fundamental to provide supportive and timely teacher feedback which can be used by the learner to make improvements. We should help students to self-correct and provide opportunities to act on feedback. Moreover, according to Brown and Knight (1994), feedback as part of the reflection process can also be an excellent motivator to promote engagement with a task or assignment. However, there is a need to explore how helpful students in a large group context find pre-lecture screencasts with an added MCQ component to be in providing them with feedback on their learning. In summary, the following questions are posed:

1. How do students use screencasts? Are the screencasts used as intentionally designed, that is, prior to lectures?

2. Is there any impact on overall learner engagement and academic achievement when a component with instantaneous feedback (such as an MCQ) is embedded into the prelecture screencast activity?

3. From a teaching perspective, what are some of the benefits of introducing pre-lecture screencasts?

\section{Methodology \\ Participants}

In the 2014-2015 academic year, the 230 undergraduates undertaking the second-year biochemistry module at an Irish university were invited to participate. Students commence this particular module from different degree programmes offered by the Faculty of Science and Engineering, including biotechnology, biological and biomedical sciences, pharmaceutical 
chemistry and general science. Thus, a diverse range of prior biology and chemistry subjectspecific knowledge was anticipated in the participants, including some learners with no previous chemistry experience at all. Following a briefing at an orientation session for the module where the tasks involved in participating in the study were explained (e.g. viewing of screencasts, option to undertake MCQs, questionnaire completion), consent forms were distributed to all students. In all, 133 students agreed to take part. However, all 230 students did have access to the screencasts irrespective of participation.

\section{Procedure}

Entry questionnaires. Participants completed a questionnaire at the start of the module which asked about their experience of large group lectures and their engagement/participation with course material inside and outside of the lecture theatre. Using a 5-point scale, participants signalled their level of agreement (from $1=$ strongly disagree to $5=$ strongly agree) for each given statement.

Screencasts and MOQs. The biochemistry students attended two 1-hour lectures on campus each week for 12 weeks. For the first four of these lectures, the new screencasts were created as prelecture resources and the module lecturer verbally encouraged all students (including those who opted not to participate in the study) to utilise the screencasts before the lecture by emphasising that the screencasts would provide information and explanations that would be essential to the upcoming lecture. In advance of the next lecture, the screencast was posted on the associated virtual learning environment space for the module (specifically, Moodle version 2.6), together with the lecture slides. Screencast-O-Matic (http://www.screencast-o-matic.com/) was employed to construct the screencasts, each of which consisted of images (obtained with permission from textbooks), text (e.g. key terms, diagram labels, novel terminology) and scripted voice-overs by the lecturer. None of the screencasts exceeded 6 minutes in length.

At the end of the screencast, the participants could access and attempt a MCQ consisting of between five to seven questions should they so wish. These quizzes were created in the Moodle environment and were drawn from a previously developed module MCQ bank. For instance, one of the questions on the chemical bonding MCQ asked, 'Which of the following terms does not refer to an example of a weak force of interaction between two biological molectules?' Most questions predominantly aimed to explore the application of the concept rather than the reproduction of facts. Linking in the MCQ served the purpose of examining common misconceptions for each topic that could then be elaborated on in the lecture setting, particularly those topics that learners appeared to be having difficulties with. Additionally, although the MCQ was voluntary and did not contribute to the module assessment, students gained immediate feedback on their progress, with topics mastered highlighted and concepts that would benefit from further review indicated. Those learners achieving full marks saw comments such as 'excellent, well done'. Advice to contact the module lecturer appeared on screen for students answering the majority of questions incorrectly.

Screencast usage. Viewing of the screencasts was analysed across three time points - midway through the module, during the final 2 weeks of the module and immediately prior to the final module examination.

Assessment. Part of the module assessment entailed a 30-minute MCQ (worth 6\% of the module) comprising 20 questions based around three biochemistry laboratory sessions and the related lectures. Module participants were assigned to one of two cohorts to complete the MCQ and each 
cohort attended on a different day. The end of module assessment (worth $70 \%$ of the module) was a 90-minute written examination with the students answering one question from each of two sections. For part A, the students had a choice of two questions.

Sudent feedback questionnaires. Participants completed anonymous feedback forms that sought to gauge their experience of the pre-lecture resources, their perceived advantages of the new approach and any suggestions for improving the activities. These were distributed by the lecturer and graduate demonstrators in the first session and again during a laboratory session towards the end of the module (but before the final examination).

\section{Findings}

\section{How do learners use screencasts?}

Once the screencasts were introduced, initial viewings by the students were high, but only for certain screencasts. For example, after being opened for 1 month, 185 views were logged for the first atoms screencast. In comparison, across the same monthly period, the carbon screencast was accessed 64 times. As shown in Table 1, as the module progressed, the number of views of the screencasts increased. For all screencasts, students watched the screencasts more often in the later stages of the module, with access figures reaching a peak immediately prior to the final module examination. Although the difference was small (the chemical bonding screencast was watched 15 more times at the end of the module compared to before the chemical bonding lecture), the expected peak in viewing in the lead up to the relevant lecture was not found.

\section{Is there any impact on overall learner engagement and academic achievement when an active component is embedded into the prelecture screencast activity?}

Learner engagement. Similar to the screencast viewings, despite the MCQs being presented as prelecture resources, many students continued to access the quizzes after the relevant lecture and on multiple occasions. As indicated in Table 2, 63 attempts at the chemical bonding MCQ were logged before the lecture, with a further 54 attempts made following the lecture. On the other hand, in some instances, participants commenced the MCQ but did not complete it. For example, the water screencast was accessed 88 times, but only 79 attempts were submitted. Frequently, however, students did go back after the lecture to complete or re-do the MCQ. There was also an improvement between the average grade of first attempts compared to last attempts for each MCQ. For example, for the water screencast, the mean percentage of first attempt correct responses was $69.41 \%$. However, as students revisited the pre-lecture screencast and indeed the associated lecture, revised the material and re-sat the MCQ, the final mean percentage was $82.75 \%$ correct.

Responses to the open-ended questionnaire items (133 participants) revealed that the students generally felt very satisfied with the newly introduced MCQs, with several students writing about the positive impact on their learning, both in terms of motivation, 'I loved your pre-lecture MCQs which were accompanied by a video. I would have liked them for all the lectures. It actually forced you to gain an understanding before the next lecture', and consolidation, 'online quiz activities (Moodle) for each different lecture topic help cement what was covered in lecture'. Some students additionally noted the teaching benefits of the pre-lecture resources: 'I liked the MCQs at the start of the module how it highlighted what was going to be covered so we knew what to expect and gave lecturer information about what to focus on'. 
Table 1. Number of pre-lecture screencast views by students across the semester.

\begin{tabular}{llll}
\hline Screencast name & Early in module & End of module & Before module exam \\
\hline Atoms & 185 & 199 & 217 \\
Chemical bonding & 100 & 104 & 115 \\
Water & 95 & 100 & 108 \\
Carbon & 64 & 67 & 70 \\
Acids and bases & 90 & 97 & 105 \\
\hline
\end{tabular}

Table 2. MCQ statistics for the five pre-lecture activities developed.

\begin{tabular}{|c|c|c|c|c|c|c|}
\hline & $\begin{array}{l}\text { Number of } \\
\text { questions }\end{array}$ & $\begin{array}{l}\text { Number of times } \\
\text { accessed before } \\
\text { lecture }\end{array}$ & $\begin{array}{l}\text { Number of } \\
\text { complete graded } \\
\text { first attempts }\end{array}$ & $\begin{array}{l}\text { Total number of } \\
\text { complete graded } \\
\text { attempts }\end{array}$ & $\begin{array}{l}\text { Aver age grade } \\
\text { of first } \\
\text { attempts }\end{array}$ & $\begin{array}{l}\text { Average grade } \\
\text { of last } \\
\text { attempts }\end{array}$ \\
\hline$\overline{\text { Atoms }}$ & 7 & 73 & 93 & 119 & $87.00 \%$ & $92.00 \%$ \\
\hline $\begin{array}{l}\text { Chemical } \\
\text { bonding }\end{array}$ & 5 & 63 & 78 & 117 & $72.56 \%$ & $83.59 \%$ \\
\hline Water & 5 & 88 & 51 & 79 & $69.41 \%$ & $82.75 \%$ \\
\hline Carbon & 5 & 61 & 41 & 59 & $60.00 \%$ & $73.66 \%$ \\
\hline $\begin{array}{l}\text { Acids and } \\
\text { bases }\end{array}$ & 5 & 112 & 79 & 110 & $79.24 \%$ & $87.09 \%$ \\
\hline
\end{tabular}

MCQ: multiple choice quiz.

When asked about how the resources could be improved, students requested integrating further MCQs or assignments into the course, some of which could be graded or non-graded. As one student stated, 'more proactive tests would be nice, but they wouldn't necessarily need to be marked, and if marked, not worth much of overall grade'. Participants less readily mentioned any disadvantages of the resources, although this may have perhaps occurred as the MCQs were voluntary and possibly were not utilised by students if they did not perceive an advantage to them.

Academic achievement. Analysis of the assessed MCQ scores for the 2014-2015 academic year indicated that the results were comparable to the previous academic year. Participants who had utilised the pre-lecture screencasts and MCQs achieved an average of 61.80\% (range, 20\%-95\%) and $65.05 \%$ (range, 20\%-90\%) on the assessed MCQ for cohorts 1 (106 students) and 2 (117 students), respectively. For the previous year, students scored averages of $65.45 \%$ and $64.45 \%$ for the two cohorts. With the end of module examination, the average mark across both sections was $54 \%$. This was slightly lower than the previous academic year where the average mark was $56 \%$. Hence, introducing the new screencasts did not seem to have a noticeable impact on overall academic achievement.

\section{From a teaching perspective, what are some of the benefits of introducing prelecture screencasts?}

One of the main benefits reported by the module lecturer was how informative the MCQ response data were in magnifying topics posing challenges to the students. Answers to specific questions were analysed and where there was a high percentage of incorrect responses returned, material relating to this particular topic was explored in the next lecture. Taking but one example, the question posed about hydrogen bonding on-in the water MCQ was answered correctly by $65.79 \%$ of the students. As hydrogen bonding is a very important concept in biochemistry, one that is essential for students to grasp, this topic was reiterated in the lecture given that nearly onethird of the group appeared to be finding it problematic to comprehend. Extending this even 
further in the lecture itself, after explaining the related material, the questions were presented as part of the lecture and the students encouraged to re-think the answer. Discussing the topic with their neighbour (during the lecture) was another activity transpiring from the MCQ response data. By show of hands, an increased number of students now appeared to have the correct answer. There was also the added benefit that students talked about the topic with a peer, which may have helped to clarify why some answers were incorrect and why the target answer was correct. Thus, the single MCQ task appeared to be the catalyst for a series of other student learning activities, all of which functioned to further the learners' understanding.

\section{Discussion and conclusion}

Within the large group setting, lack of engagement is a common area of concern (Carini et al., 2006). One of the purposes of this study was to help students develop the necessary prior knowledge to facilitate their learning through use of pre-lecture screencasts. The study further sought to determine the usage patterns of such screencasts by the learners. Additionally, in an effort to make the screencast activity somewhat less passive, pre-lecture MCQs were implemented and the feedback generated from the response data used to inform future lectures.

Broadly speaking, the study suggests that pre-lecture resources such as screencasts and MCQs can be useful aids to facilitate learner engagement. Through the response patterns to the MCQs and the accompanying questionnaires that participants completed, a greater awareness for the lecturer of the types of challenges experienced by the students became possible. Without ascertaining what the existing levels of prior knowledge are like for the group, time could be spent unconstructively on topics that learners are already proficient in. Thus, it was very important to listen to the student feedback and take on board suggestions to improve their learning in the future, particularly in upcoming lectures. Timely engagement with students and giving both learners and facilitators an opportunity to act on feedback has long been advocated in the literature (Boud and Molloy, 2013; Nicol, 2009). This study explored one way in which this is possible, with the chosen method being enthusiastically received and (most importantly, perhaps) used by the students. Ideally then, any approach that is developed should not only be informative, in the sense of helping learners and lecturers differentiate what is 'known' from what is 'unknown' to guide future learning activities, but should be transformative as well with an aim of advancing the 'known'.

This study represented the first step in an attempt to help learners in a large group learning context acquire some of the necessary foundational knowledge that would hopefully enable them to more easily grasp associated concepts as explored in future lectures. Despite the finding that students who did and did not have access to the pre-lecture resources achieved comparable average marks, what was apparent was that the learners were generally willing to try out and engage with the voluntary resources, albeit in a manner that was somewhat disparate with the original intention. The data suggest that even though the screencasts were promoted as prelecture resources, this did not appear to be how the students solely used them. Rather than oneoff, before-lecture resources, the students continuously returned to the screencasts at other intervals during the module. It should be noted, however, that some of the resource views could be the same student accessing the screencast on multiple occasions, while other students could have downloaded the screencast for offline use so that the viewing frequencies could have been higher still.

Although the students did not use the screencasts exclusively before the associated lecture, it may be suggested that their repeated use of the screencasts across the module was still encouraging. Students instead accessed the resources throughout the duration of the module, particularly immediately before the final examination. These findings are in line with the 
proposal that multiple, recurrent viewings of multimedia resources such as screencasts and animations may contribute to optimal learning (Reindl et al., 2015). There is scope here to examine why this was the case. Factors such as a lack of lecture preparation time, a preference to attend the lecture first before undertaking related lecture tasks and ambiguity surrounding how the resource could help from an early stage may all be possibilities. This finding does reiterate the importance of being aware of how learners do in practice use learning tools (Struyven et al., 2012), something which should be considered when designing and implementing any new approach in the classroom.

Reflecting on the effects of the new pre-lecture screencasts and MCQs, it was evident that most of the students did actively engage with the optional activities. Students attempted to gauge their prior knowledge on the topic and revised the concepts they were struggling with. Similar high levels of student engagement with screencasts that only marginally contributed to assessment grades were reported by Seery and Donnelly (2012). Taken together, such findings suggest that there may be other factors (apart from formative assessment) influencing why (or why not) students may use such additional learning resources. Furthermore, introducing the prelecture resources also led to some more active engagement in the formal lecture with students having some familiarity with the topic from the outset. As a consequence, the resources were deemed to be a successful aid to support learners, particularly in regard to bridging the background diversity levels of the mixed ability class. One of the most prominent anecdotal observations was that the students adopted a more proactive approach to the material (e.g. asking more questions in and after class) and took responsibility for their learning early in the module rather than waiting until just before the examinations. The feedback from the participants suggested that the students themselves placed a high importance on the opportunity to self-test and validate their level of understanding and topic knowledge.

Concurrent benefits from a teaching perspective were also apparent, especially the useful, near real-time information provided by the MCQ response data on the sections of the course that students understood or struggled with. Based on this information, the lecturer could refer back to the challenging MCQs and go through the common misconceptions that arose, spending greater time on these topics and offering direct feedback on areas of uncertainty. Conversely, those topics that the students all scored well in could be addressed more time-efficiently in the formal lecture setting.

Despite the screencasts being made available on the virtual learning space, this did not mean that students would automatically watch them. There seemed to be other factors influencing this decision. One possibility perhaps could be that if students felt comfortable and knowledgeable about the topic already, this may have resulted in less inclination to view the resource, even though it might have some benefits (e.g. learning something that they did not know already, such as a new term). One of the limitations of this study was that we did not ask learners to rate or self-assess their understanding of particular topics prior to the introduction of the screencasts. Doing so may have shed light on why the initial screencast viewings before the lectures were not consistently high for all screencasts. Other limitations included the small size of the sample given the number of students in the cohort. Repeating the study with a larger sample size could provide a broader perspective of learner views, particularly regarding some of the reasons underlying whether or not pre-lecture resources are employed. Furthermore, in terms of data analysis, it would have been useful to compare how the students felt about the lectures before and after the new resources were introduced. Another was that only one module was selected for the study with the same lecturer developing the screencasts, teaching the lectures and analysing the surveys. It is plausible that students' responses to the research were influenced by their relationship with the lecturer. Future studies would benefit from a separate source and delivery of the teaching and the research activities. 
Overall, although an improvement in academic achievement was not observed following the introduction of the screencasts, the data did suggest that the students liked the new resources (with many recognising the value of such resources for their own learning), which is a promising start. There are opportunities now to revisit how the resources might be used in a way that is still enjoyable for the learners, but which might also be associated with strengthening their academic performance. Hudson et al. (2015) compare changes made to any course to be akin to a marathon as opposed to a sprint. The race has now begun. To move forward, we need to explore how the resources could be employed in a way that would contribute more directly to success on a module. For many, the use of the resources is optional for students. Thus, it remains to be seen whether the level of participation with the resources would be higher and more effective if the screencasts and associated MCQs were included as part of the continual assessment on any module. Future work is needed to investigate this. Among the other questions raised by this research are whether there are any student characteristics that particularly encourage learners to use the pre-lecture resources. For instance, is less familiarity associated with greater use of the resources, and do learners with at least some prior discipline-related knowledge employ the resources to the same extent as learners with little or no knowledge?

Finally, the approach undertaken was designed for the collective group of learners in the sense that there was a focus in the pre-lecture resources on enhancing knowledge of topics that would likely present conceptual challenges for a large proportion of students. Typically, these tended to be curriculum areas that students from previous cohorts indicated to the lecturer they had struggled to comprehend. Thus, there is scope to examine how such pre-lecture resources could be modified to support learners as individuals, especially at various junctures throughout a module when their learning requirements may be very different - for example, needing to learn unfamiliar terminology at the start of a module or needing to make connections to previous content midway through a module. Davies et al. (2013) highlighted how the array of technology available can contribute to making an increasingly personalised learning experience a possibility for students. Tailoring the resources more closely to explicit individual learning needs could enhance the relevance of the resource which may transpire to be a further source of motivation for students to engage with the activities.

\section{Funding}

The author(s) received no financial support for the research, authorship and/or publication of this article.

\section{References}

Ausubel DP (1968) Educational Psychology: A Cognitive View. New York: Holt, Rinehart \& Winston.

Badenhorst E, Mamede S, Hartman N, et al. (2015) Exploring lecturers' views of first-year health science students' misconceptions in biomedical domains. Advances in Health Sciences Education: Theory and Practice 20(2): 403-20.

Baepler P, Walker JD and Driessen M (2014) It's not about seat time: Blending, flipping, and efficiency in active learning classrooms. Computers \& Education 78: 227-36.

Boud D and Falchikov N (1989) Quantitative studies of student self assessment in higher education: A eritical analysis of findings. Higher Education 18(5): 529-49.[AQ2]

Boud D and Molloy E (2013) Rethinking models of feedback for learning: The challenge of design. Assessment \& Evaluation in Higher Education 38(6): 698-712.

Brown S and Knight P (1994) Assessing Learners in Higher Education. London: Kogan Page.

Burchfield CM and Sappington J (2000) Compliance with required reading assignments. Teaching of Psychology 27(1): 58-60.

Burnstein RA and Lederman LM (2001) Using wireless keypads in lecture classes. The Physics Teacher 39(1): 8-11. 
Caldwell J, Zelkowski J and Butler M (2006) Using personal response systems in the classroom. In: WVU technology symposium, Morgantown, WV, 11 April.

Campbell C and Monk S (2015) Introducing a learner response system to pre-service education students: Increasing student engagement. Active Learning in Higher Education 16(1): 25-36.

Cantor AD, Eslick AN, Marsh EJ, et al. (2015) Multiple-choice tests stabilize access to marginal knowledge. Memory \& Cognition 43(2): 193-205.

Carini RM, Kuh GD and Klein SP (2006) Student engagement and student learning: Testing the linkages. Research in Higher Education 47(1): 1-32.

Clump MA and Doll J (2007) Do low levels of reading course material continue? An examination in a forensic psychology graduate program. Journal of Instructional Psychology 34(4): 242-6.

Coppola BP and Krajcik JS (2014) Discipline-centered post-secondary science education research: Distinctive targets, challenges and opportunities. Journal of Research in Science Teaching 51(6): 67993.

Coticone SR (2013) Utility of self-made crossword puzzles as an active learning method to study biochemistry in undergraduate education. Journal of College Science Teaching 42(4): 33-7.

Davies RS, Dean DL and Ball N (2013) Flipping the classroom and instructional technology integration in a college-level information systems spreadsheet course. Educational Technology Research \& Development 61(4): 563-80.

Exeter DJ, Ameratunga S, Ratima M, et al. (2010) Student engagement in very large classes: The teachers' perspective. Studies in Higher Education 35(7): 761-75.

Fulton K (2012) Upside down and inside out: Flip your classroom to improve student learning. Learning and Leading with Technology 39(8): 12-7.

Gilboy MB, Heinerichs S and Pazzaglia G (2015) Enhancing student engagement using the flipped classroom. Journal of Nutrition Education and Behavior 47(1): 109-14.

Herreid CF and Schiller NA (2013) Case studies and the flipped classroom. Journal of College Science Teaching 42(5): 62-6.

Hudson DL, Whisenhunt BL, Shoptaugh CF, et al. (2015) Change takes time: Understanding and responding to culture change in course redesign. Scholarship of Teaching and Learning in Psychology. Available at: http://dx.doi.org/10.1037/stl0000043 (accessed 26 October 2015).

Knight JK and Wood WB (2005) Teaching more by lecturing less. Cell Biology Education 4(4): 298-310.

Kowalski P and Kujawski Taylor A (2009) The effect of refuting misconceptions in the introductory psychology class. Teaching of Psychology 36(3): 153-9.

Lane ES and Harris SE (2015) A new tool for measuring student behavioural engagement in large university classes. Journal of College Science Teaching 44(6): 83-91.

Lasry N, Guillemette J and Mazur E (2014) Two steps forward, one step back. Nature Physics 10(6): 402-3.

Lopez EJ, Shavelson RJ, Nandagopal K, et al. (2014) Ethnically diverse students' knowledge structures in first-semester organic chemistry. Journal of Research in Science Teaching 51(6): 741-58.

Mohorovičić S and Tijan E (2011) Using screencasts in computer programming courses - Preliminary results. In: II Proceedings of the 22nd EAEEIE annual conference EAEEIE, Faculty of Electrical Engineering and Computer Science, University of Maribor. Available at: http://eaeeie2011.unimb.si/eaeeie2011_submission_48.pdf (accessed 7 August 2015).

Moravec M, Williams A, Aguilar-Roca N, et al. (2010) Learn before lecture: A strategy that improves learning outcomes in a large introductory biology class. CBE: Life Sciences Education 9(4): 473-81.

Morris C and Chikwa G (2014) Screencasts: How effective are they and how do students engage with them? Active Learning in Higher Education 15(1): 25-37.

Muller DA, Bewes J, Sharma MD, et al. (2008) Saying the wrong thing: Improving learning with multimedia by including misconceptions. Journal of Computer Assisted Learning 24(2): 144-55.

Mulryan-Kyne C (2010) Teaching large classes at college and university level: Challenges and opportunities. Teaching in Higher Education 15(2): 175-85.

Nicol DJ (2009) Transforming assessment and feedback: Enhancing integration and empowerment. Available at: http://www.reap.ac.uk/Portals/101/Documents/REAP/transforming-assessment-andfeedback.pdf (accessed 7 August 2015).

Nicol DJ and Macfarlane-Dick D (2004) Rethinking formative assessment in HE: A theoretical model and seven principles of good feedback practice. Available at: http://www.enhancementthemes.ac.uk/docs/ 
workshop/rethinking-formative-assessment-a-theoretical-model-and-seven-principles-of-good-feedbackpractice-paper.pdf?sfvrsn=24 (accessed 7 August 2015).

Opdecam E and Everaert P (2012) Improving student satisfaction in a first year undergraduate team accounting course by team learning. Issues in Accounting Education 27(1): 53-82.

Reindl KM, White AR, Johnson C, et al. (2015) The virtual cell animation collection: Tools for teaching molecular and cellular biology. PLoS Biology 13(4): e1002118.

Seery MK (2009) The role of prior knowledge in undergraduate performance in chemistry - A correlationprediction study. Chemistry Education: Research and Practice 10(3): 227-32.

Seery MK and Donnelly R (2012) The implementation of pre-lecture resources to reduce in-class cognitive load: A case study for higher education chemistry. British Journal of Educational Technology 43(4): 667-77.

Struyven K, Dochy F and Janssens S (2012) Explaining students' appraisals of lectures and studentactivating teaching: Perceived context and student characteristics. Interactive Learning Environments 20(5): 391-422.

Stull JC, Majerich DM, Bernacki ML, et al. (2011) The effects of formative assessment pre-lecture online quizzes and student-initiated inquiries to the instructor on academic achievement. Educational Research and Evaluation 17(4): 253-62.

Thompson RA and Zamboanga BL (2004) Academic aptitude and prior knowledge as predictors of student achievement in introduction to psychology. Journal of Educational Psychology 96(4): 778-84.

Vital F (2012) Creating a positive learning environment with the use of clickers in a high school chemistry classroom. Journal of Chemical Education 89(4): 470-3.

Wijtmans M, van Rens L and van Muijlwijk-Koezen JE (2014) Activating students' interest and participation in lectures and practical courses using their electronic devices. Journal of Chemical Education 91(11): 1830-7.

\section{Biographical notes}

Gemma K Kinsella, an Assistanta Lecturer in Food and Pharmaceutical Biochemistry, works with undergraduate and postgraduate students. Her scientific research interests encompass both chemical biology and early stages of drug design. Her pedagogical research is concerned with learning technologies which encourage engagement. Address: School of Food Science and Environmental Health, College of Sciences and Health, Dublin Institute of Technology, Cathal Brugha Street, Dublin 1, Ireland. [email: Gemma.kinsella@dit.ie]

Catherine Mahon teaches on the Professional Certificate in Teaching and Learning and the Postgraduate Diploma in Higher Education at Maynooth University. Her research interests include exploring approaches to help students with the transition to higher education. Address: Centre for Teaching and Learning, Maynooth University, National University of Ireland Maynooth, Maynooth, Co. Kildare, Ireland. [email: catherine.m.mahon@nuim.ie]

Seamus Lillis is a consultant working in community development. His research interests are in applications of action research. Address: Dr Seamus Lillis \& Associates, UKDublin, Ireland. [email: slillis@eircom.net] 